\title{
Construction of Ecological Network of Regional Expressway Landscape Based on Sustainable Development*
}

\author{
Hui Feng \\ College of Urban and Environmental Science \\ Northwest University \\ Xi'an, China 710127 \\ Shaanxi Normal University \\ Xi'an, China 710062
}

\author{
Kang Liu \\ College of Urban and Environmental Science \\ Northwest University \\ Xi'an, China 710127
}

\begin{abstract}
Aiming at the demand of ecological network of expressway landscape in modern society, this paper follows the principle of highway network construction under sustainable development, completes the analysis of expressway landscape ecological network pattern, and proposes key indicators and corresponding calculation methods. According to the actual regional division of expressways in a certain area, the ecological network segmentation resistance assignment table is formulated to ensure the natural ecology and sustainable development of the expressway landscape ecological design.
\end{abstract}

Keywords-sustainable development; expressway landscape; ecological network construction

\section{INTRODUCTION}

At the beginning of the expressway, society only pursues the function of its high-speed traffic. With the improvement of social civilization, people's requirements for expressways have paid more and more attention to the overall landscape effect of the expressway and the ecological network formed by the surrounding environment in addition to its function. The road landscape ecological network design came into being. The construction of highway landscape ecological network is a comprehensive consideration covering many aspects such as road design, landscape planning, natural science, history, aesthetics, etc. When constructing the overall ecological network of highway landscape in a certain range of areas, the following design principles must be met:

- Functional guarantee: the expressway is an important traffic artery of a country or region, which is used for driving large and small vehicles in the process of national economic construction. Its design should always put the functional principle of the road in the first place.

- Ecological guarantee: the main body of the expressway is mostly in a natural ecological area. The landscape design of the expressway must be in line $17 \times 29$

*Fund Project: Xi'an Social Science Planning Fund. Project Number: with nature, respect nature, and try to ensure that the original natural ecology is not destroyed.

- Difference guarantee: most high-level roads like expressway have large spans, often running through many provinces and cities. Different regions have different styles based on different geographical environments. Highway landscape design should reflect the principle of regional differences.

- Comprehensive guarantee: the landscape ecological planning of expressway is a comprehensive project involving multidisciplinary knowledge areas. A comprehensive consideration of social, economic and ecological factors is necessary.

\section{PRINCIPLES FOR THE CONSTRUCTION OF ECOLOGICAL NETWORKS UNDER SUSTAINABLE DEVELOPMENT}

The International Union for Conservation of Nature in 1980 discussed the relationship between economic development and nature, ecology, and society. For highway landscape design, sustainable development includes three aspects: sustainability, fairness and integrity. Development and reservation are key issues that require consideration under the sustainable development approach. A good balanced relation can achieve a good road view and continue it. Sustainable development is to balance the highway construction and the preservation of the scenery along the way, and to deal with the economic growth caused by modern transportation, when considering the damage it will bring to the traditional scene. The literature "Economics and Natural Resources: Insufficiency and Development" suggests that sustainable development should maximize the value of economic benefits when protecting the natural environment resources, so that the sustainable development of the environment can be achieved.

The natural beauty of the region is left behind by the process of social development. It belongs not only to our generation, but also to our children and grandchildren Modern people should respect and protect them, so that 
future generations can enjoy the same rights, instead of only learning through books and pictures, to achieve fairness in development. The rapid development of transportation and the protection of the environment constitute a unified whole. Historic buildings, streets, customs, and living conditions are indispensable parts of the expressway landscape, and they should be properly preserved. The development of the economy is also concerned about the practical benefits of the today's social residents, and we must make overall plans to achieve the integrity of development.

\section{ANALYSIS OF THE LANDSCAPE ECOLOGICAL NETWORK PATTERN OF EXPRESSWAY}

In the process of expressway construction, it is necessary to pay attention to the ecological nature of the landscape and put environmental protection in the first place in order to achieve sustainable development, develop without damaging the resources of future generations, and develops without damaging environment. Plant protection in expressway is also an important point. It is necessary to give priority to the historical legacy, and to decorate and beautify the places lacking the landscape by planting new plants to create a partial microclimate. It helps to protect the soil, prevent soil erosion, and increase the experience of scenery along the way. It is suggested to adhere to the principle of economic applicability with the strategy based on economy to promote the development of industrial economy along the route by moderate development supplemented by humanized tourism support, and carry out accurate economic development positioning. Nowadays, it is necessary to combine the sustainable development of expressways with economic growth points such as tourism. Accurate economic development positioning plays a forward-looking role in the construction of expressways. Starting from the type of users, distance planning, transportation types and other aspects of expressways, the direction of construction and planning of expressway will be finalized, and the purposeful and conscious development will be carried out.

\section{A. Selection of Expressway Landscape Index}

In terms of the measurement of the landscape pattern, the landscape index can better reflect the composition characteristics of the expressway structure and express the spatial characteristics. The landscape index obtained by using highly concentrated landscape pattern information is used as an indicator for quantitative evaluation of expressway landscape pattern in this study. The corresponding landscape index was selected to make quantitative evaluation of its landscape pattern.

The landscape index can be divided into three categories: patch-level index, class-level index and landscape-level index. The research mainly starts from the class level and landscape level, and combines the local actual situation to select the landscape index which is more commonly used in the previous literature and has obvious ecological significance. The characteristics of regional landscape patterns are described from different aspects:
1) Number of patches $(N P)$ : It indicates the total number of patches in the landscape. In general, the $\mathrm{NP} \geq 1$, and the larger the NP is, the higher the fragmentation degree of the landscape type in the region is, so it can be used as an indicator to measure the degree of landscape fragmentation.

2) Patch density $(P D)$ : The expression is:

$$
\mathrm{PD}=\frac{N}{A}
$$

$\mathrm{N}$ is the number of patches, and A refers to the total area. Generally, the larger the value of PD is, the higher the degree of landscape fragmentation is.

3) Ratio of patches in landscape area (PLAND): The expression is:

PLAND $=P_{t}=\frac{\sum_{j=1}^{n} a_{i j}}{A} \times(100)$

$\mathrm{N}$ represents the number of patches, $\mathrm{i}$ represents the landscape type, ${ }^{a_{\text {if }}}$ represents the area of the patch $\mathrm{j}$ in the landscape type $\mathrm{i}$, and A represents the total area of the landscape. PLAND is a landscape component that reflects the proportion of a landscape type in the landscape. The value $0<$ PLAND $\leq 1$ is taken.

$$
\begin{aligned}
& \text { 4) Largest patch index (LPI): The expression is: } \\
& \mathrm{LPI}=\frac{\max \left(\partial_{\overline{\mathrm{V}}}\right)}{A} \times(100)
\end{aligned}
$$

It is the area ratio of a certain type of landscape patch in the overall landscape, $\max \left(\partial_{i}\right)$ indicates the maximum patch area in landscape type $\mathrm{i}$, and $\mathrm{A}$ is the total area of the landscape.

5) Interspersion and Juxtaposition Index (IJI): The expression is:

$$
\mathrm{IJI}=\frac{-\Sigma_{k=1}^{m}\left[\left(\frac{\varepsilon_{i k}}{\Sigma_{k=1}^{m} \varepsilon_{i k}}\right) \ln \left(\frac{\varepsilon_{i k}}{\Sigma_{k=1}^{m} \varepsilon_{i k}}\right)\right]}{\ln (m-1)} \times(100)
$$

$\mathrm{m}$ is the number of landscape types, and $e_{\mathrm{ik}}$ is the length of the adjacent edges of the landscapes $i$ and $k$. The calculation method is: the negative value of the sum of the other kinds of adjacent edge length values adjacent to a certain kind dividing the total length of the patch before multiplying by the natural logarithm of the value divides the number of types and minus 1 to get the natural logarithm; the overall interspersion and juxtaposition between different plaque types can be reflected.

6) Effective particle size area (MESH): The expression is:

$$
\mathrm{MESH}=\frac{\sum_{\mathrm{i}=1}^{\mathrm{n}} \sum_{j=1}^{n} a_{\mathrm{ij}}^{2}}{A}
$$

The calculation method is the ratio of the square of the patch area to the total area, which is used to describe the degree of landscape fragmentation.

7) Patch cohesion index: The expression is: 
COHESION $=\left[1-\frac{\sum_{j=1}^{n} p_{i j}^{*}}{\sum_{j=1}^{n} p_{i j}^{*} \sqrt{a_{i j}^{*}}}\right] \cdot\left[1-\frac{1}{\sqrt{Z}}\right]^{-1}$

$P_{\text {诵 }}^{*}$ represents the ratio of the perimeter of the patch $\mathrm{j}$ of the landscape type $i$ to the side length of the grid. $a_{i j}^{*}$ represents the area to side length ratio of the patch $j$ of the landscape type $\mathrm{i}$, and $\mathrm{Z}$ represents the number of grids in the landscape. The COHESION index can indicate the degree of physical connection between patch types at the type level, reflecting the degree of fragmentation of the landscape. The greater the value is, the better the connectivity is.

At the landscape level, select:

1) Number of patches (NP): It indicates the total number of patches in the landscape. In general, the $\mathrm{NP} \geq 1$, and NP is positively correlated with the degree of landscape fragmentation. The larger the NP, the higher the fragmentation degree of the landscape type in the region, so it can be used as a index of to measure the degree of landscape fragmentation.

2) patch density $(P D)$ : The expression is:

$$
\mathrm{PD}=\frac{\mathbb{N}}{A}
$$

$\mathrm{N}$ is the number of patches, and A refers to the total area. Generally, the larger the PD is, the higher the degree of fragmentation of the landscape is.

\section{3) Shannon diversity index (SHDI): The expression is:}

$$
\mathrm{SHDI}=-\sum_{\mathrm{i}=1}^{\mathrm{m}}\left(P_{\mathrm{i}} \ln P_{\mathrm{i}}\right)
$$

$\mathrm{m}$ represents the number of landscape types, and $P_{i}$ represents the percentage of patch type $i$ and its landscape. SHDI can reflect the change in the number and proportion of landscape types. In the landscape composed of different landscape types, when the proportion of landscape types is the same, the SHDI value is the highest, the uncertainty is higher, and the degree of landscape fragmentation increases.

4) Contagion index (CONTAG): The expression is:

$$
\text { CONTAG }=\left[1+\frac{\sum_{i=1}^{m} \Sigma_{k=1}^{m}\left[\left[\left(p_{i}\right)\left(\frac{g_{i k}}{\sum_{k=1}^{m} g_{i n}}\right)\right] \cdot\left[\ln \left(p_{i}\left(\frac{g_{i k}}{\sum_{k=1}^{m} g_{i k}}\right)\right)\right]\right.}{2 \ln (m)}\right] \text {. }
$$

$\mathrm{m}$ is the number of patch types, $P_{i}$ represents the percentage of the patch type $\mathrm{i}$ and its landscape, and $g_{i \mathrm{ik}}$ represents the number of adjacent cells between the patch type $i$ and the patch type. The CONTAG index can indicate the aggregation or contagion of different landscape types in the landscape. Generally, the CONTAG index is positively correlated with the landscape connectivity.

5) Effective particle size area (MESH): The expression is:

$$
\text { MESH }=\frac{\sum_{i=1}^{n} \Sigma_{j=1}^{n} a_{i j}^{2}}{A}
$$

The calculation method is the ratio of the square of the patch area to the total area, which describes the degree of fragmentation of the landscape.

6) Aggregation index (AI): The expression is:

$$
\mathrm{AI}=\left[\frac{g_{\text {ii }}}{\max g_{\text {ii }}}\right] \cdot(100)
$$

$g_{i \mathrm{ii}}$ is the number of approximate connected patches of landscape type i. AI indicates the aggregation and dispersibility of patches. The larger the value is, the more pixels in the common boundaries in this type are.

7) The expression of patch cohesion degree index (COHESION)

COHESION $=\left[1-\frac{\sum_{j=1}^{n} p_{i j}^{*}}{\sum_{j=1}^{n} p_{i j}^{*} \sqrt{a_{i j}^{*}}}\right] \cdot\left[1-\frac{1}{\sqrt{Z}}\right]^{-1} \cdot(100)$

$P_{\text {: }}^{*}$ represents the ratio of the perimeter of the patch $\mathrm{j}$ of the landscape type $i$ to the side length of the grid. $a_{i j}^{*}$ represents the area to side length ratio of the patch $j$ of the landscape type $\mathrm{i}$, and $\mathrm{Z}$ represents the number of grids in the landscape. The COHESION index can indicate the degree of physical connection between patch types at the type level, which can reflect the degree of fragmentation of the landscape. The larger the value is, the better the landscape connectivity is.

\section{B. Data Analysis of Landscape Index}

Data preprocessing can be performed through ArcGIS 10.4 , and the landscape index of the expressway can be calculated by using Fragstats 4.2.

TABLE I. LANDSCAPE-LEVEL LANDSCAPE INDEX OF EXPRESSWAY IN A CERTAIN AREA OF WESTERN CHINA IN 2017

\begin{tabular}{|l|l|}
\hline \multicolumn{1}{|c|}{ landscape index } & \multicolumn{1}{c|}{ result } \\
\hline Number of patches (NP) & 175217 \\
\hline patch density (PD) & 20.4473 \\
\hline Contagion index (CONTAG) & 39.5279 \\
\hline Patch cohesion index & 99.5087 \\
\hline Effective particle size area (MESH) & 23031.9606 \\
\hline Shannon Diversity Index (SHDI) & 1.4055 \\
\hline Aggregation index (AI) & 86.6027 \\
\hline
\end{tabular}

${ }^{\text {a. }}$ Source: Shaanxi Statistical Yearbook (2017) 
TABLE II. TYPE-LEVEl LANDSCAPE INDEX OF EXPRESSWAY IN A CERTAIN AREA OF WESTERN CHINA IN 2017

\begin{tabular}{|l|l|l|l|l|l|l|l|}
\hline $\begin{array}{c}\text { type of } \\
\text { land use }\end{array}$ & $\begin{array}{c}\text { Number of } \\
\text { patches (NP) }\end{array}$ & $\begin{array}{c}\text { patch } \\
\text { density (PD) }\end{array}$ & $\begin{array}{c}\text { ratio of patches } \\
\text { in landscape } \\
\text { area (PLAND) }\end{array}$ & $\begin{array}{c}\text { Largest } \\
\text { patch index } \\
\text { (LPI) }\end{array}$ & $\begin{array}{c}\text { Interspersion and } \\
\text { Juxtaposition } \\
\text { Index (IJI) }\end{array}$ & $\begin{array}{c}\text { Effective } \\
\text { particle size area } \\
\text { (MESH) }\end{array}$ & $\begin{array}{c}\text { Patch cohesion } \\
\text { index } \\
\text { (COHESION) }\end{array}$ \\
\hline farmland & 51281 & 5.9844 & 0.3560 & 4.5595 & 90.0339 & 4938.6479 & 99.6028 \\
\hline forest land & 16681 & 1.9466 & 0.1045 & 1.9847 & 74.4249 & 429.7163 & 98.3834 \\
\hline $\begin{array}{l}\text { construction } \\
\text { land }\end{array}$ & 29100 & 3.3959 & 0.2341 & 6.5276 & 76.4805 & 4589.0658 & 99.3998 \\
\hline water area & 59871 & 6.9868 & 0.2748 & 11.8148 & 74.0690 & 13062.5255 & 99.6547 \\
\hline others & 18284 & 2.1337 & 0.3069 & 0.3317 & 81.1866 & 12.0050 & 90.1271 \\
\hline
\end{tabular}

It can be seen from "Table I" and "Table II" that the total number of patches (NP) is 175,217 in the landscape pattern index at the landscape level. Since the study area is the entire expressway, the number of patches is relatively large. It means that there is a certain landscape fragmentation phenomenon in the area. However, the aggregation index (AI) and the patch cohesion index (COHESION) are large, which indicates that although there is a certain landscape fragmentation phenomenon in the region, the landscape connectivity is still good, and the fragmented landscape does not weaken the material-energy communication among patches. In the landscape index at type level, the number of farmland patches and water patches are more than 50000 and their patch density (PD) is also the highest of all landscape types, indicating the two types of landscapes in the region has more severe fragmentation than other types of landscapes. From the point of view of the IJI, the value of the farmland landscape type is the highest, and the protection concept of the original natural ecological environment in the area can also be seen. From the patch cohesion index (COHESION), except other types of landscapes, the number can reach 98 or more, indicating that the degree of landscape fragmentation in the study area has not affected the connectivity of the landscape, and the material energy transmission between the patches is kept well.

\section{SPATIAL PATTERN SEGMENTATION OF EXPRESSWAY LANDSCAPE ECOLOGICAL NETWORK}

Landscape ecological network is of great significance in landscape ecology. The migration corridor of natural animals is the core element of the construction of expressway landscape ecological network, which cannot be ignored. More and more scholars recognize the importance of ecological corridors. Since the actual corridor data for animal migration is difficult to obtain, the study mostly simulates the migration corridor based on the minimum cost distance model. The model based on the minimum cost distance mainly includes the selection of specific species and ecological source points, landscape resistance analysis, and distance threshold selection. Different organisms, different ecological habitats, different landscape resistance values, and different distance thresholds, etc., can form different corridors, and thus construct different ecological network. In the process of ecological network construction, the choice of ecological source and the construction of resistance system have a great impact on the results. Therefore, how to select the ecological source more scientifically is particularly important. Most of the previous studies took nature reserves, scenic spots, forest parks, and large water sources as ecological sources, which have certain subjectivity. In the study, through the characteristics of morphology, various types of patch that have a certain meaning for the circulation of material energy are identified at the pixel level to determine the core region. The $\mathrm{BC}$ index and $\mathrm{Dg}$ index of each patch were normalized by MSPA analysis, and the results of the two indexes were combined to select a certain ecological source in the study area, so that the subjectivity in selecting source in the past was changed. The reliability of the research results can be guaranteed. Because the expressway has a great influence on the ecological patches, the original large-scale ecological patches will be segmented, which will result in disorder of the ecosystems in the study area. Therefore, there are various road factors in the selection of resistance indicators, including: elevation, gradient, type of land use, the distance from the road, etc., and the resistance factors are analyzed according to the Delphi method to determine the corresponding weights as shown in "Table III".

TABLE III. RESISTANCE AsSIGNMENT TABLE

\begin{tabular}{|c|c|c|c|}
\hline resistance factors & classification index & $\begin{array}{l}\text { resistance } \\
\text { value }\end{array}$ & weight \\
\hline elevation & $\begin{array}{l}<50 \\
50 \sim 150 \\
150 \sim 250 \\
250 \sim 350 \\
>350\end{array}$ & $\begin{array}{l}1 \\
2 \\
3 \\
4 \\
5\end{array}$ & 0.15 \\
\hline gradient $\left({ }^{\circ}\right)$ & $\begin{array}{l}<3 \\
3 \sim 8 \\
8 \sim 15 \\
15 \sim 25 \\
>25\end{array}$ & $\begin{array}{l}1 \\
2 \\
3 \\
4 \\
5\end{array}$ & 0.10 \\
\hline land-use type & $\begin{array}{l}\text { forest land } \\
\text { farmland } \\
\text { other land } \\
\text { water area } \\
\text { construction land }\end{array}$ & $\begin{array}{l}1 \\
2 \\
3 \\
4 \\
5 \\
\end{array}$ & 0.18 \\
\hline $\begin{array}{l}\text { the distance from } \\
\text { railway }\end{array}$ & $\begin{array}{l}>2000 \\
1500 \sim 2000 \\
1000 \sim 1500 \\
500 \sim 1000 \\
<500\end{array}$ & $\begin{array}{l}1 \\
2 \\
3 \\
4 \\
5\end{array}$ & 0.15 \\
\hline $\begin{array}{l}\text { the distance from } \\
\text { main road }\end{array}$ & $\begin{array}{l}>2000 \\
1500 \sim 2000 \\
1000 \sim 1500 \\
500 \sim 1000 \\
<500\end{array}$ & $\begin{array}{l}1 \\
2 \\
3 \\
4 \\
5\end{array}$ & 0.14 \\
\hline
\end{tabular}




\begin{tabular}{|l|l|l|l|}
\hline resistance factors & classification index & $\begin{array}{c}\text { resistance } \\
\text { value }\end{array}$ & weight \\
\hline the distance from & $>2000$ & 1 & 0.14 \\
secondary main & $1500 \sim 2000$ & 2 & \\
road & $1000 \sim 1500$ & 3 & \\
& $500 \sim 1000$ & 4 & \\
& $<500$ & 5 & 0.14 \\
the distance from & $>2000$ & 1 & \\
expressway & $1500 \sim 2000$ & 2 & \\
& $1000 \sim 1500$ & 3 & \\
& $500 \sim 1000$ & 4 & \\
& $<500$ & 5 & \\
\end{tabular}

When selecting different cumulative impedance values to simulate the ecological corridor, the original single corridor has some redundancy, and even some corridors have begun to separate. Compared with the traditional single corridor, it can better reflect the movement rules of species in the process of migration. However, due to the small number of green core patches in the central part of the study area, the connectivity between the patches in the north and south regions is still relatively weak. To ensure the stability of the ecosystem in the study area, it is necessary to carry out restoration work for the vegetation in cities where expressway cross and repair the connectivity of the corridor, to maintain the ecological stability of the study area and play a very important role in the protecting species diversity in the region.

\section{CONCLUSION}

The expressway ecological landscape design within the region pays attention to the harmony, integrity, diversity, safety and sustainability of the design. These characteristics are important principles of highway landscape design. Harmony, integrity and diversity are the primary design conditions for expressway landscape design while safety and sustainability are necessary design conditions for expressway landscape design. This paper studies the function and content of expressway landscape design from the perspective of sustainable development. The role of protecting natural ecology and reconciling highways and natural landscapes are essential functions of expressway landscape design, which are the important conditions for the expressway landscape to develop towards ecological landscape development. The ecological landscape emphasizes organic cooperation and coordination by different ecosystems, namely the internal environment and the external environment, and the coexistence of human and nature symbiosis, advocating people returning to nature and integrating into nature. This design concept is in line with the long-term planning goals of highway landscape design. Whether it is the choice of green plants or the design of highway routes, we should adhere to the principle of adapting to nature and protecting natural ecology and minimize the traces of manual construction to make the expressway truly "grow" out of the natural ecology.

\section{REFERENCES}

[1] Hamilton R S, Harrison R M. Special issue: expressway and urban pollution[J]. Total Environment, 1996(18):1-6. (in Chinese)
[2] Tang Zhenxing, Du Li. The Application of the Landscape Ecology in Highway Landscape Environmental Planning [J]. Shandong Forestry Science and Technology, 2005, (5): 75. (in Chinese)

[3] Xu Xiaogang et al. Discussion on the road environmental destruction and vegetation restoration [J]. Chinese Landscape Architecture, 2005(1): 51. (in Chinese)

[4] Zhang Yang, Yuan Weining, Li Ping. Research on landscape design method of retaining wall in road and bridge engineering [J]. Journal of Northwestern Institute of Architectural Engineering, 2000, 17(3): 54-57. (in Chinese)

[5] Liu Juan, Gao Wei. Research on Landscape Greening Design of Expressway Interchange Area[J]. Shanxi Architecture, 2007, 33(23): 33-3. (in Chinese)

[6] He Fudao. Preliminary study on slope protection and reinforcement of expressway [J]. Yunnan Communication Science and Technology. 2001, 17 (4): 24-26. (in Chinese)

[7] Lu Hongqi. Points for design of landscape and virescence[J] Transportation Standardization, 2006, 08 (42): 18-24. (in Chinese)

[8] Li Xi. Thoughts on the planning and design of expressway landscape greening [J]. East China Highway, 2006, 01 (11). (in Chinese)

[9] Feng Zhigao, Wu Ming. Research on sustainable ecological road construction [J]. Science and Technology Innovation Herald, 2008 (18): $155-156$. (in Chinese)

[10] Schaeffer, K. H, Eliott Sclar. Access for all: Transportation and urban growth[J]. Md.:Penguin,1975. (in Chinese) 